\title{
MEASURED THERMAL AND FAST NEUTRON FLUENCE RATES FOR ATF-1 HOLDERS DURING ATR CYCLE 158B/159A
}

L.D. Smith, D.T. Miller, and B.J. Walker

November 2016

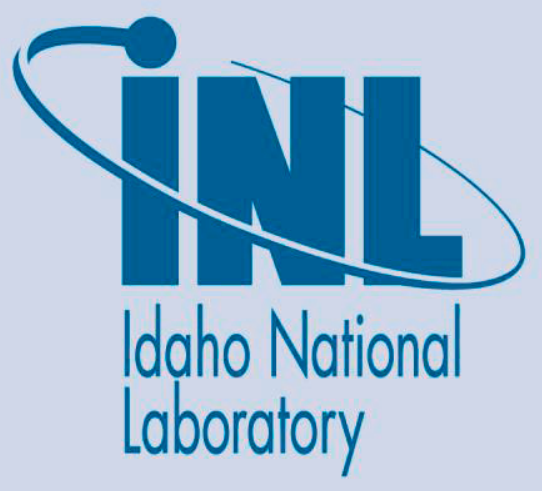

The INL is a U.S. Department of Energy National Laboratory operated by Battelle Energy Alliance 


DISCLAIMER
This information was prepared as an account of work sponsored by an
agency of the U.S. Government. Neither the U.S. Government nor any
agency thereof, nor any of their employees, makes any warranty, expressed
or implied, or assumes any legal liability or responsibility for the accuracy,
completeness, or usefulness, of any information, apparatus, product, or
process disclosed, or represents that its use would not infringe privately
owned rights. References herein to any specific commercial product,
process, or service by trade name, trade mark, manufacturer, or otherwise,
does not necessarily constitute or imply its endorsement, recommendation,
or favoring by the U.S. Government or any agency thereof. The views and
opinions of authors expressed herein do not necessarily state or reflect
those of the U.S. Government or any agency thereof.


INL/EXT-16-40576

Revision 0

\title{
MEASURED THERMAL AND FAST NEUTRON FLUENCE RATES FOR ATF-1 HOLDERS DURING ATR CYCLE 158B/159A
}

\author{
L.D. Smith, D.T. Miller, and B.J. Walker
}

November 2016

\begin{abstract}
Idaho National Laboratory
Idaho Falls, Idaho 83415
\end{abstract}

http://www.inl.gov 
Prepared for the

U.S. Department of Energy

Office of Nuclear Energy

Under DOE Idaho Operations Office

Contract DE-AC07-05ID14517 


\title{
MEASURED THERMAL AND FAST NEUTRON FLUENCE RATES \\ FOR ATF-1 HOLDERS DURING ATR CYCLE 158B/159A \\ $01 / 03 / 16$ thru $06 / 28 / 16$
}

\author{
L.D. Smith, D.T. Miller, and B.J. Walker
}

This report contains the thermal $(2200 \mathrm{~m} / \mathrm{s})$ and fast $(\mathrm{E}>1 \mathrm{MeV})$ neutron fluence rate data for the ATF-1 holders located in core for ATR Cycle 158B/159A which were measured by the Radiation Measurements Laboratory (RML) as requested by the Power Reactor Programs (ATR Experiments) Radiation Measurements Work Order.

This report contains measurements of the fluence rates corresponding to the particular elevations relative to the $80-\mathrm{ft}$. core elevation. The data in this report consist of (1) a table of the ATR power history and distribution, (2) a hard copy listing of all thermal and fast neutron fluence rates, and (3) plots of both the thermal and fast neutron fluence rates. The fluence rates reported are for the 158B average power level given by the table of power history and distribution. These calculated fluence rates do not consider the effects of the shift in power split among individual lobes between the two cycles. Prior to this reporting period, the RML reevaluated the sensitivity of the pressurized ionization chamber used for the absolute normalization of the flux profiles. This reevaluation with initial findings detailed in a recent correspondence (CCN 239287) results in a decrease of approximately $10 \%$ thermal and $15 \%$ fast reported flux.

All "BR" holder monitor wires for this cycle are 56.375 inches long. This length allows measurements from 31.17 inches above core midplane to 19.81 inches below core midplane. The distance from the end of the wires to the first count position was 4.25 inches for all wires counted from this cycle.

The monitors were located in the outward small I-holes, I-21 and I-24. Thermal neutron fluence was determined based on the activation of the CoAl wires and resonance corrections determined in the irradiation of Cycle 152A when the RML measured cadmium-covered as well as bare neutron monitors in the Southwest, Southeast, and $\mathrm{H}$ positions at the Center lobe to determine the division in neutron energy between epithermal and thermal neutrons. For more information please refer to letter "Radiation Measurements Laboratory measurements of in core ATR physics testing during cycle 152A. The measured values documented in RML procedure, "ACMM-3600, Flux Monitoring," will be used indefinitely until further measurements supersede the current values. Fast neutron fluence was determined using the activation of nickel wires. Typically, a fission spectrum averaged cross section $(\mathrm{E}>1 \mathrm{MeV})$ is used as determined in detailed measurements described in "ATR Neutron Spectral Characterization," which gives an effective cross section of $97 \mathrm{mb}$ for the small I-holes. However, those measurements were performed with unfueled experiments. The fast fluence values reported here use a perturbed $114 \mathrm{mb}$ effective $>1$ $\mathrm{MeV}$ spectrum averaged cross section for the small I-holes based on MCNP simulations for a previous fueled experiment in the I-24 position. Refer to "LWR - ATR Irradiation Measured Thermal and Fast Neutron Fluence Rates ATR CYCLE 133A 04/19/04 thru 05/17/04" for more information. 


\section{References}

- D.T. Miller, “Initial findings regarding Radiation Measurements Laboratory's pressurized ionization chamber sensitivity discrepancy related to increasing trend in fast and thermal flux per megawatt," correspondence, letter file DTM-04-16 (CCN 239287), 27 October 2016.

- C.C. Jensen, "Radiation Measurements Laboratory measurements of in core ATR physics testing during cycle 152A", correspondence, letter file CCJ-001-13 (CCN 229533), 24 January 2013.

- J.W. Rogers and R.A. Anderl, “ATR Neutron Spectral Characterization”, INEL-95/0494, November 1995.

- L.D. Smith and C.C. Jensen, "LWR - ATR Irradiation Measured Thermal and Fast Neutron Fluence Rates ATR Cycle 133A 04/19/04 thru 05/17/04”, INEEL/INT-0402291, September 2004.

- ACMM-3600, 2015, “Flux Monitoring,” Rev. 11, 22 October 2015. 


\section{DEFINITIONS OF REPORTED INFORMATION ON PRINTED PAGES}

1. CYCLE: The identification code given to a specific period of operation of the ATR for which the data in this report applies.

2. POSITION: The identification code given to a specific location in the ATR core area where neutron monitors were located and for which the data associated with the code apply. The letter code identifies the lobe and the number code identifies a monitor position.

3. MONITOR ID: The identification code given to a specific neutron monitor holder. The code is stamped on the holder. The letter code identifies the type of holder and the number is unique to allow tracking of the neutron monitors and their data.

4. EFPD: The acronym for "Effective Full Power Days" which is the effective number of days the ATR operated at the average total core power level of the cycle. This value is obtained from the ATR power history and distribution.

5. AVERAGE MW: The average power level (in megawatts) at which the ATR lobe operated during the cycle. The values used for NW, NE, C, SW, and SE lobes are obtained from the ATR power history and distribution. The values used for the other lobes and core positions are determined as follows:

$$
\begin{aligned}
P_{N} & =\frac{P_{N E}+P_{N W}+P_{C}}{3} \\
P_{E} & =\frac{P_{N E}+P_{S E}+P_{C}}{3} \\
P_{S} & =\frac{P_{S E}+P_{S W}+P_{C}}{3} \\
P_{W} & =\frac{P_{N W}+P_{S W}+P_{C}}{3}
\end{aligned}
$$

\begin{tabular}{|l|l||l|l|l|l|l|l|}
\hline Position & Lobe & Position & Lobe & Position & Lobe & Position & Lobe \\
\hline A1-A8 & C & B1 or B2 & NE & B9 & N & I21 & NE \\
\hline A9 & NE & B3 or B4 & SE & B10 & E & I22 & SE \\
\hline A10 & SE & B5 or B6 & SW & B11 & S & I23 & SW \\
\hline A11 & SW & B7 or B8 & NW & B12 & W & I24 & NW \\
\hline A12 & NW & & & & & & \\
\hline
\end{tabular}

6. DATE: The calendar dates corresponding to the outage and operating time of the cycle. These dates include the forced outage time associated with the cycle as well as the operating time. 
7. ELEVATION: The vertical position associated with the neutron fluence rate relative to the $80 \mathrm{ft}$. elevation of the ATR core. The elevation values are in inches and negative values are below the $80 \mathrm{ft}$. elevation (commonly referred to as centerline). The elevation values are established reference elevation points specified as follows:

\begin{tabular}{|l|l|l|}
\hline Holder Type & Reference Elevation & Drawing Number \\
\hline BR & $78.000 \mathrm{ft}$. & 035561 \\
\hline
\end{tabular}

Position of the BR holder relative to the centerline was determined using DWG-604281, "ATR ATF Experiment Final Assembly". Using the dimensions of the monitor holders, the location of the monitor wire in the holder, the length of the wire and the distance between the measurements along the wire an elevation value for each fluence rate is determined. An evaluation of the elevation tolerances for typical holders follows:

Holder fabrication

Cutting the monitor wire to length

Wire alignment in the holder

Mounting the wire to the scanner

Scanning control

Scanner home positioning

Stackup of the safety rod components (estimated)

Position of the safety rod relative to the $80 \mathrm{ft}$. (core

centerline) during operation

95\% confidence bound

Maximum error

${ }^{*}$ This estimate will be revised after an actual measurement is made

** This estimate does not include variations due to thermal and hydraulic effects

These elevation tolerances include only what are considered to be random errors.

Systematic errors or biases may also occur due to information input. However, procedural controls minimize this information input error.

8. "THERMAL": The equivalent $2200 \mathrm{~m} / \mathrm{s}(0.025 \mathrm{eV})$ neutron fluence rate assuming a Maxwellian distribution for the thermalized neutrons at $20.44{ }^{\circ} \mathrm{C}$. The fluence rate is determined from the ${ }^{59} \mathrm{Co}(\mathrm{n}, \gamma){ }^{60} \mathrm{Co}$ reaction rate assuming a 37 barn $2200 \mathrm{~m} / \mathrm{s}$ cross section for the reaction. Corrections for the epithermal reaction rate are made based on cadmium ratio measurements at each position of the fluence rate measurement. All fluence rates are in units of neutrons per $\mathrm{cm}^{2}$ per second. 
9. "FAST": The equivalent $>1 \mathrm{MeV}$ fission neutron energy flux assuming a pure ${ }^{235} \mathrm{U}$ fission spectrum neutron energy distribution. The fluence rate is determined from the ${ }^{58} \mathrm{Ni}(\mathrm{n}, \mathrm{p}){ }^{58} \mathrm{Co}$ reaction rate assuming a 0.114 barn effective $>1 \mathrm{MeV}$ fission spectrum averaged cross section for the reaction with a $66.3 \%$ branching ratio to the ground state. Corrections for the burnout of the ${ }^{58} \mathrm{Co}$ isomers are made based on the measured $2200 \mathrm{~m} / \mathrm{s}$ fluence rate, the exposure duration and the burnout cross sections of the isomers [1650 barns (71 days), $1.7 \mathrm{E}+5$ barns ( 9.1 hours)] at each position of the fluence rate measurement.

10. CENTERLINE FLU. RATE: The neutron fluence rate at the elevation assignment nearest to the ATR core centerline elevation (0.0).

11. AVG. MAX. FLU. RATE: The average of the highest three adjacent values.

12. MAX. FLU. RATE/MW (AVG.): The average maximum fluence rate divided by the average power level (MW) of the lobe or position.

13. K FACTOR: The conversion factor determined from the neutron monitor activity for converting the net count rate at each elevation to the absolute reaction product $\left({ }^{60} \mathrm{Co}\right.$ or $\left.{ }^{58} \mathrm{Co}\right)$ radioactivity per unit mass of the monitor material $(\mathrm{d} / \mathrm{s} / \mathrm{mg})$.

14. RESONANCE CORRECTION: The fractional correction factor used to correct the ${ }^{59} \mathrm{Co}(\mathrm{n}, \gamma){ }^{60} \mathrm{Co}$ reaction rate for the epithermal neutron response at the position where the neutron monitor was located during irradiation. This correction factor was determined from cobalt "cadmium ratio" measurements at the same spatial location for the monitor geometry and atom density.

15. C/L BURNOUT CORRECTION: The correction factor for the burnout (transmutation) of the reaction products $\left({ }^{60} \mathrm{Co},{ }^{58} \mathrm{Co},{ }^{58 \mathrm{~m}} \mathrm{Co}\right)$ of the neutron monitors during the cycle irradiation at the centerline fluence rate elevation. The burnout correction factors for other elevation assignments will vary (nonlinearly) depending on the thermal neutron fluence rates and cycle durations.

16. BACKGROUND (counts/sec.): The wire scanner detector background environment counting rate at the time the neutron monitor wires were scanned.

17. CHECK SOURCE (counts/sec.)

Date and hour: The wire scanner detector check source count rate on the day the neutron monitor wires were scanned. The check source is a radioactive $\left({ }^{60} \mathrm{Co}\right)$ cobalt-aluminum wire mounted in a fixture which reproducibly positions it over the detector collimator. This check source is used to test counting functions (gain and stability) of the scanner counting system. The count rate is corrected for background and decay corrected to 05/01/88, 12:00. 


\section{ON PLOTS}

18. REACTOR: Identification of the reactor with which the data are associated (normally ATR).

19. CYCLE POWER: The total megawatt days of power produced during the reactor cycle. This value is normally obtained from the ATR power history and distribution information supplied by PRP.

20. MATERIAL: The element name of the neutron monitor material. The "thermal" neutron monitor material is normally an alloy $(\mathrm{CoAl})$ of cobalt $(\mathrm{Co})$ and aluminum $(\mathrm{Al})$ where the weight percent is given preceding the percent (\%) symbol.

21. EXPERIMENT: The identification code given to the experiment located in the loop. This information is provided by PRP. 
POWER HISTORY AND DISTRIBUTION

CYCLE $158 \mathrm{~B} / 159 \mathrm{~A}$

$01 / 03 / 16$ thru $06 / 28 / 16$

\begin{tabular}{lllllll}
\hline & NW & NE & C & SW & SE & TOTAL \\
\hline MWD & 993.5 & 1048.1 & 1064.4 & 1281.3 & 1291.9 & 5679.2 \\
MWD/44 = EFF. Te & 22.58 & 23.82 & 24.19 & 29.12 & 29.36 & \\
EFF. Te./EFPD & 0.404 & 0.426 & 0.433 & 0.521 & 0.526 & \\
MWD/EFPD = Avg. Power (MW) & 17.78 & 18.76 & 19.05 & 22.93 & 23.12 & 101.64 \\
\hline
\end{tabular}

The fluence rate determinations used the following power history which includes the intercycle shutdown as well as the power disruption during cycle 159A:

\begin{tabular}{lccl}
\hline & Duration [days] & Power [MW] & Power factor \\
\hline & 51.40 & 101.65 & 1.0 \\
76.10 & 0.00 & 0.0 \\
6.20 & 48.39 & 0.476 \\
& 3.73 & 0.00 & 0.0 \\
& 0.82 & 48.39 & 0.476 \\
& 0.77 & 148.61 & 1.462 \\
EFPD & 55.87 & & \\
Max. Power [MW] & & 148.61 & \\
\hline
\end{tabular}




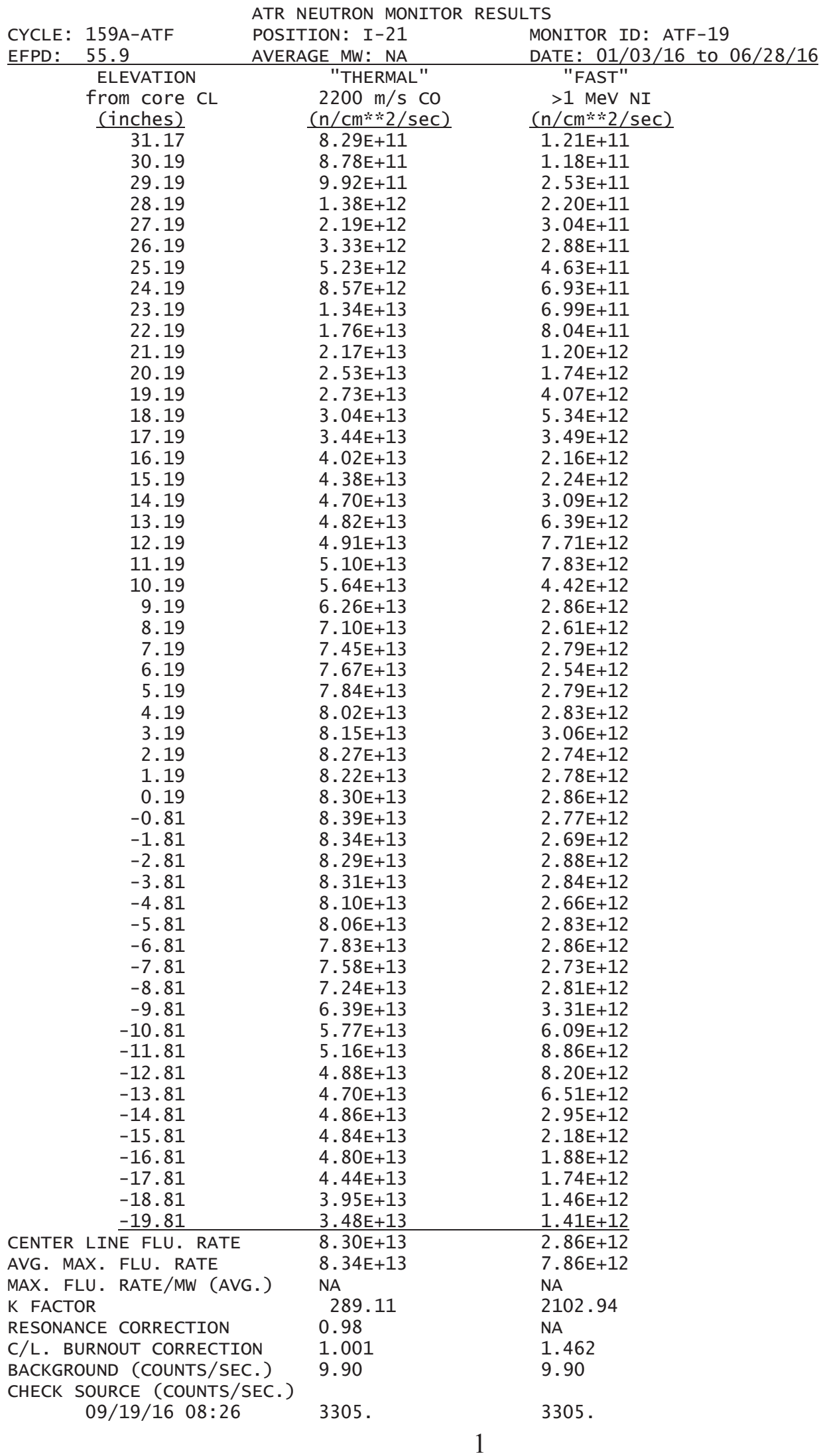




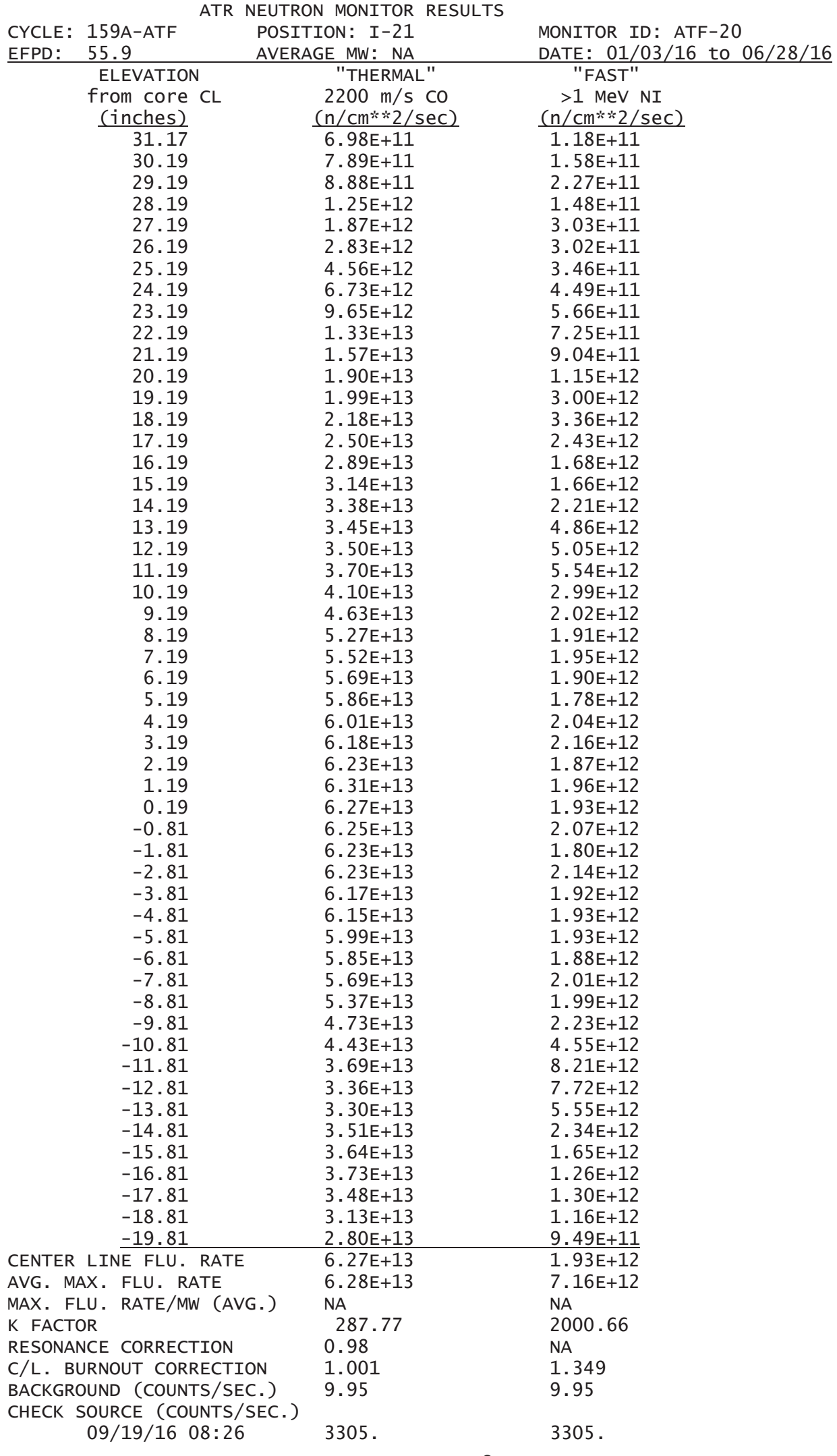




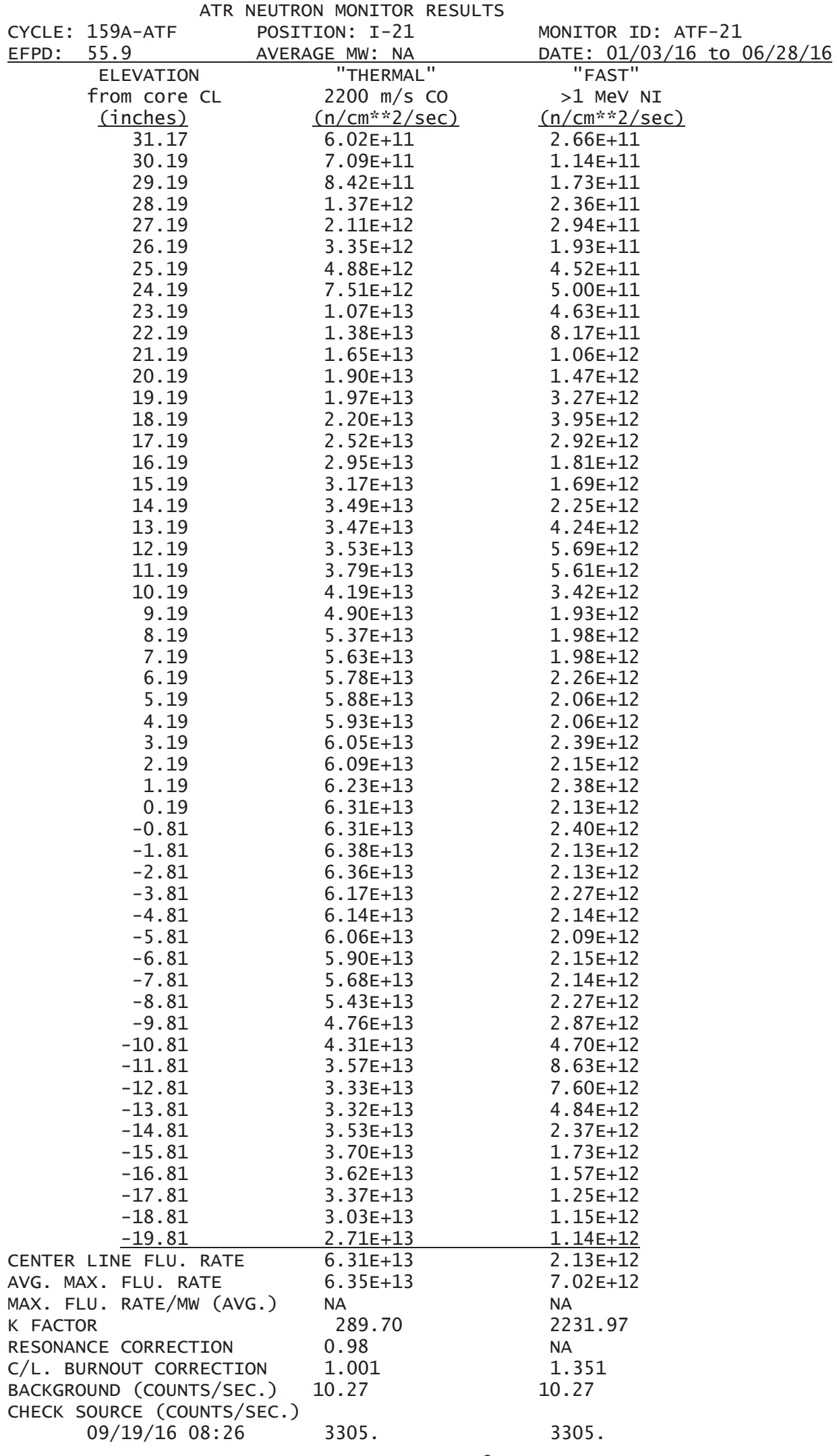




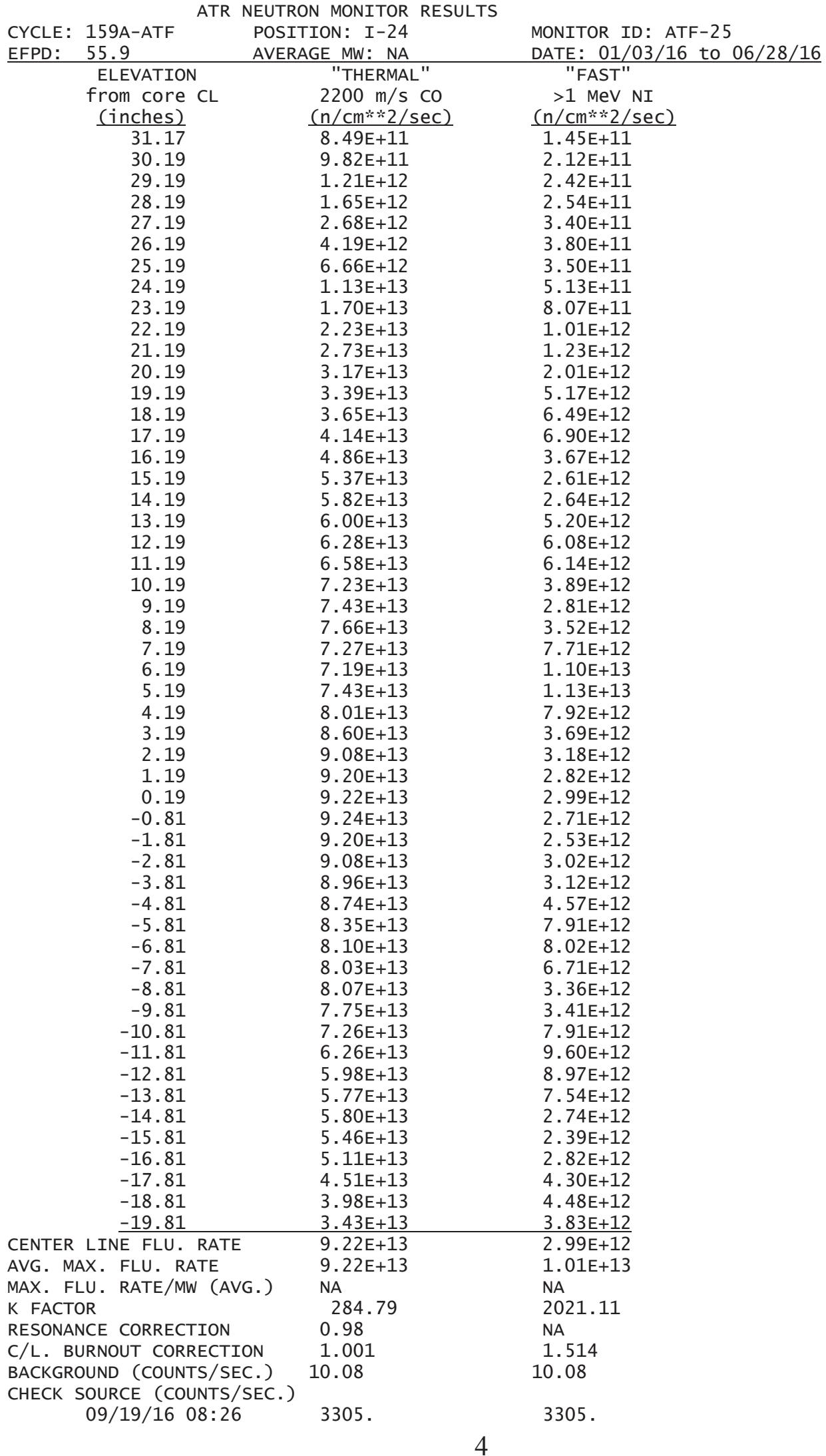




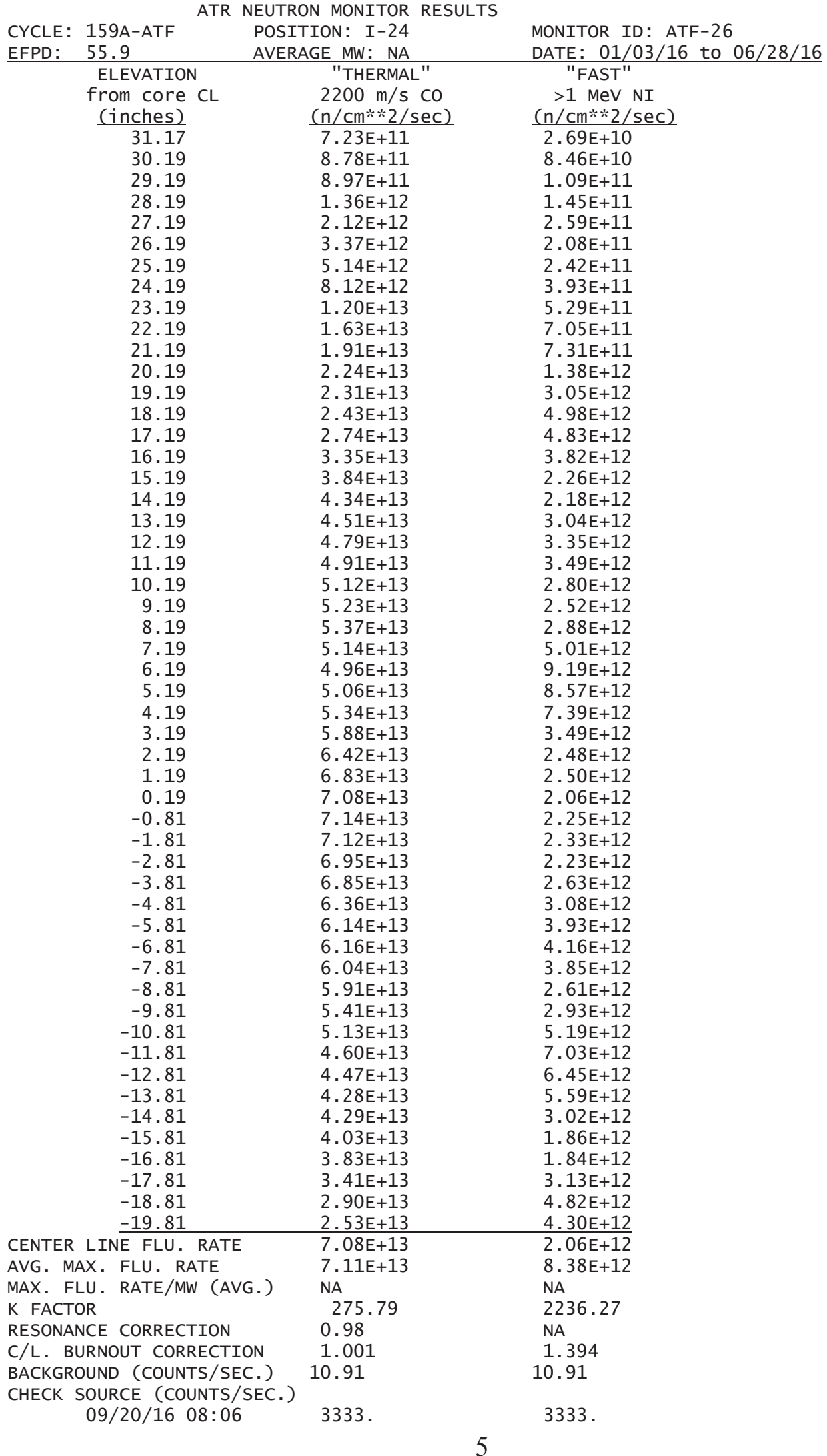




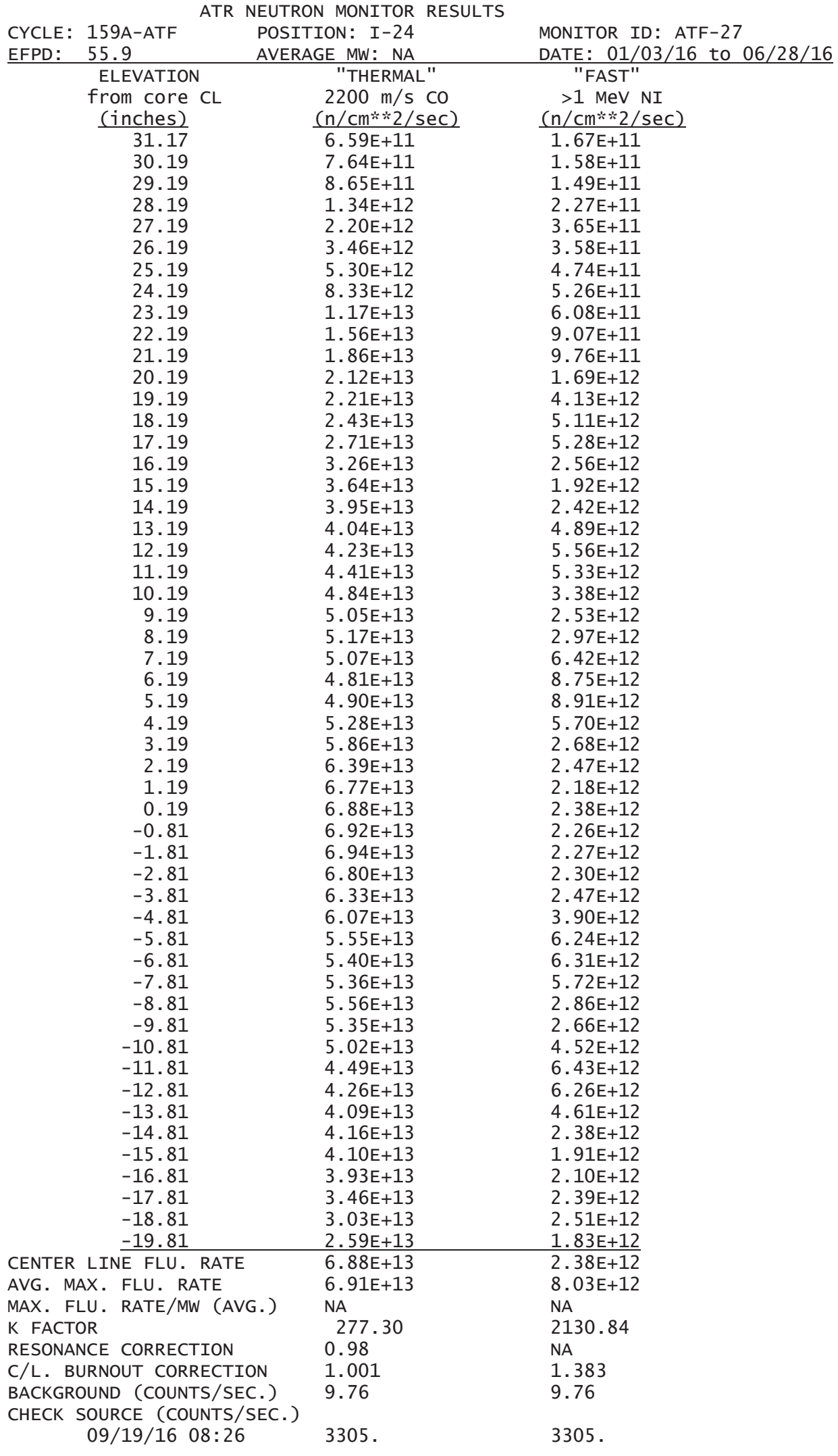




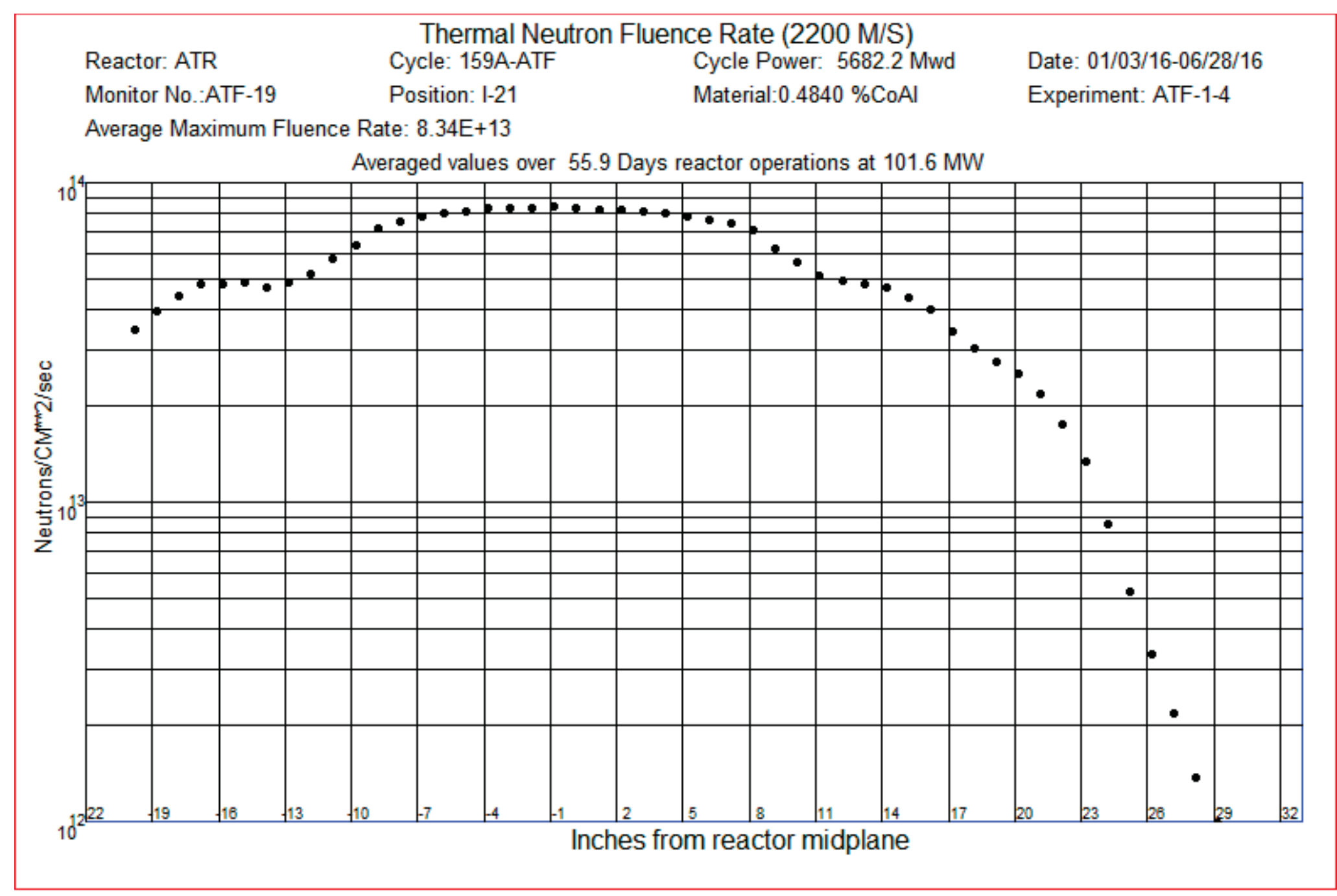




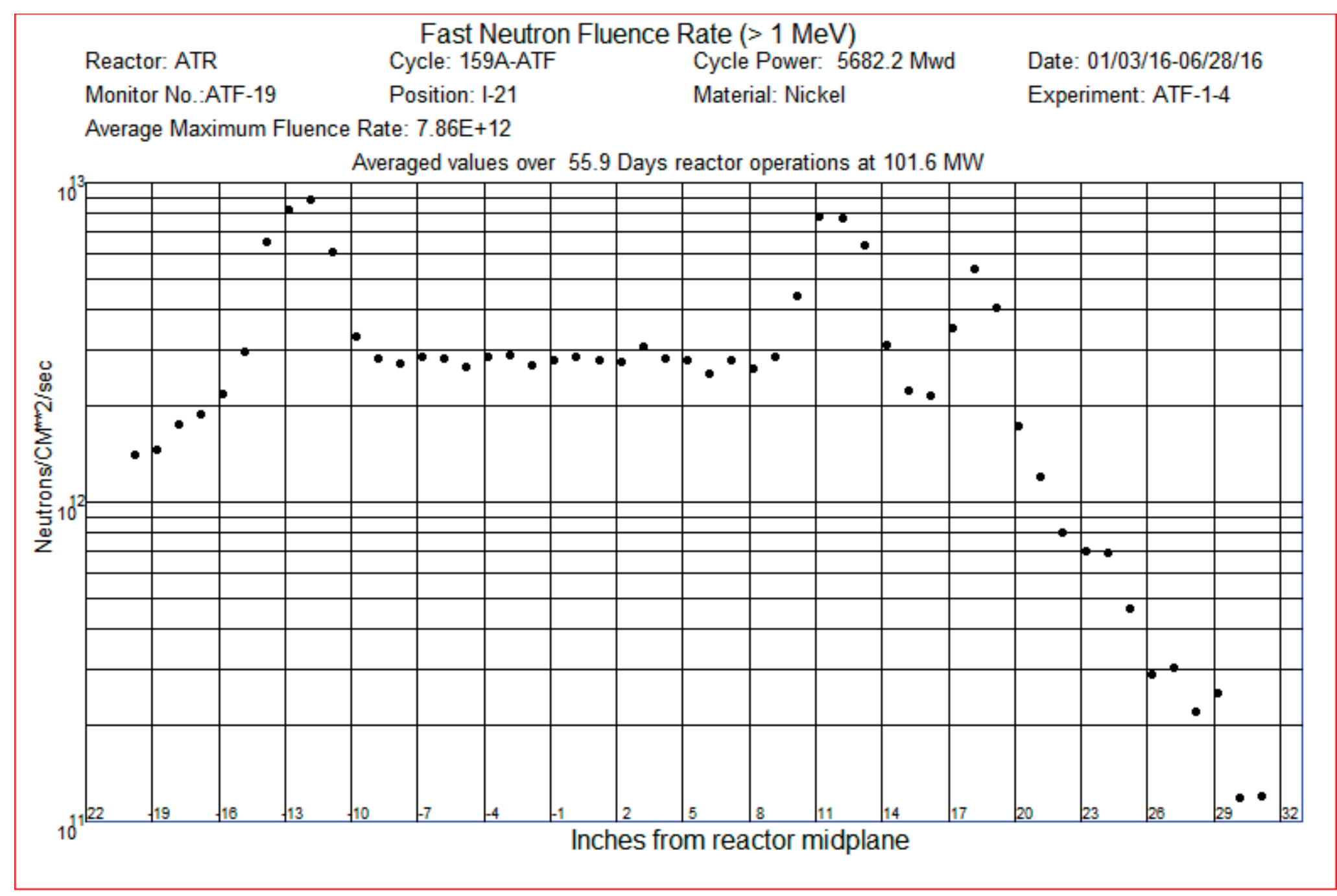




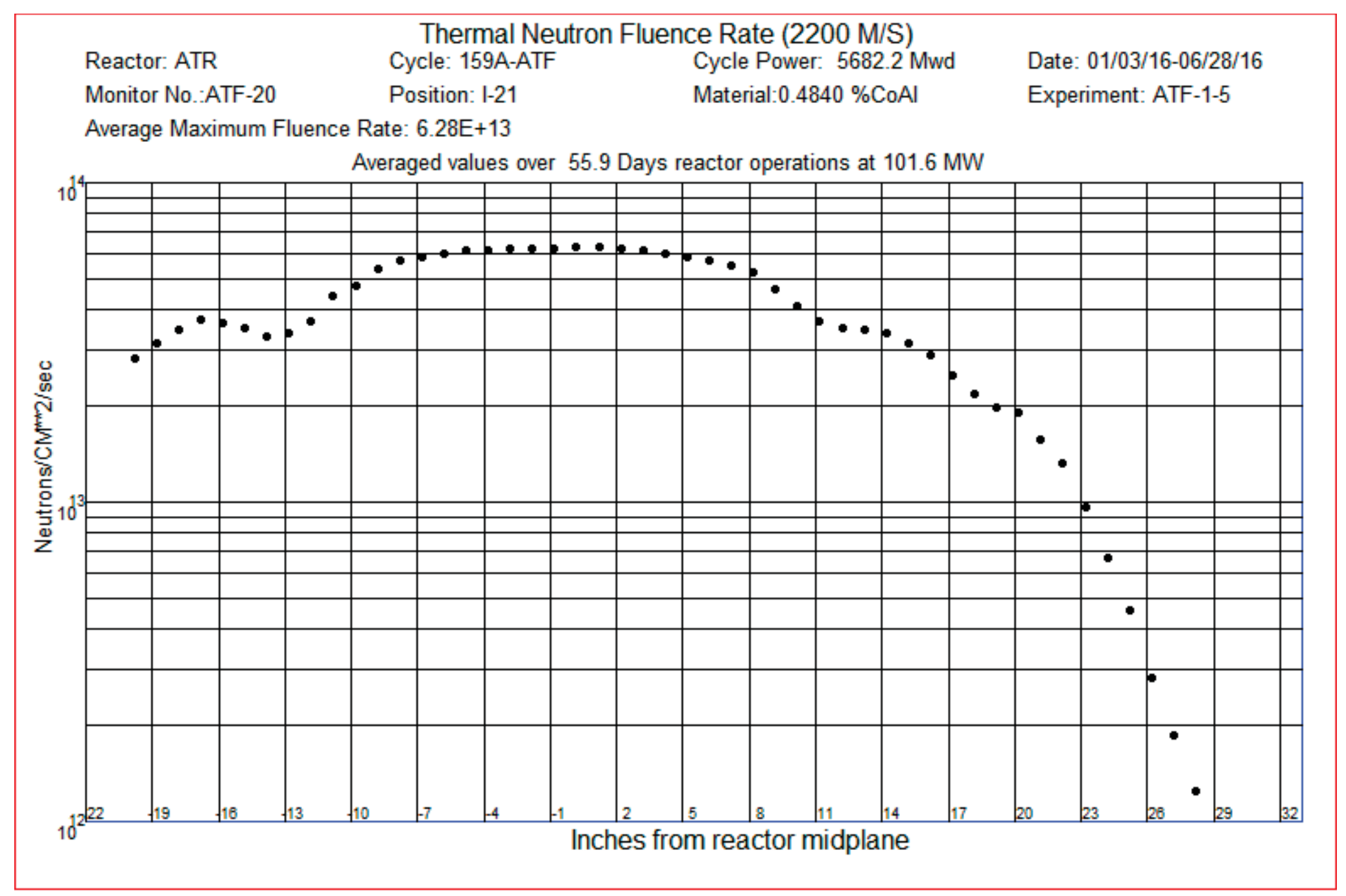




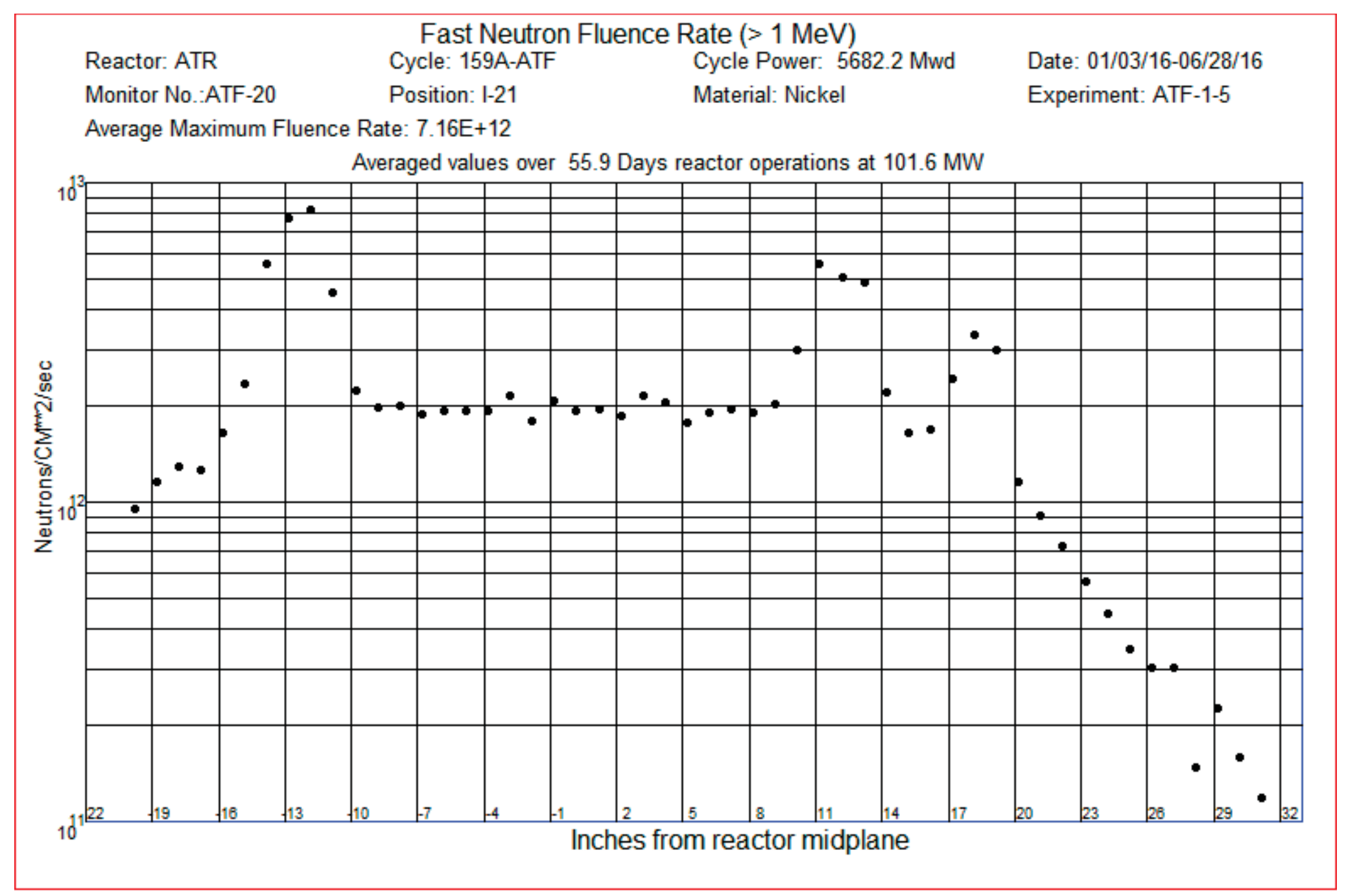




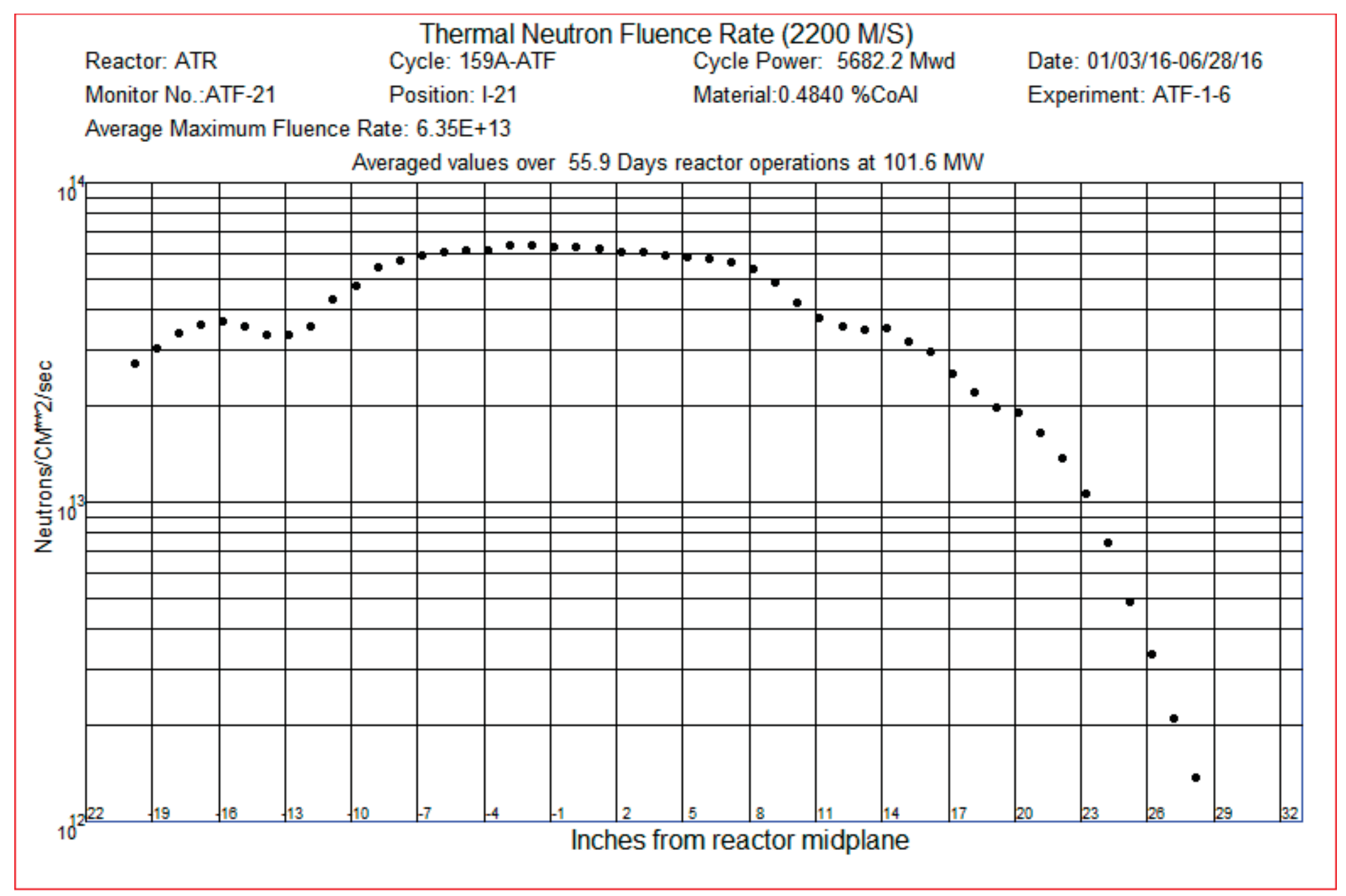




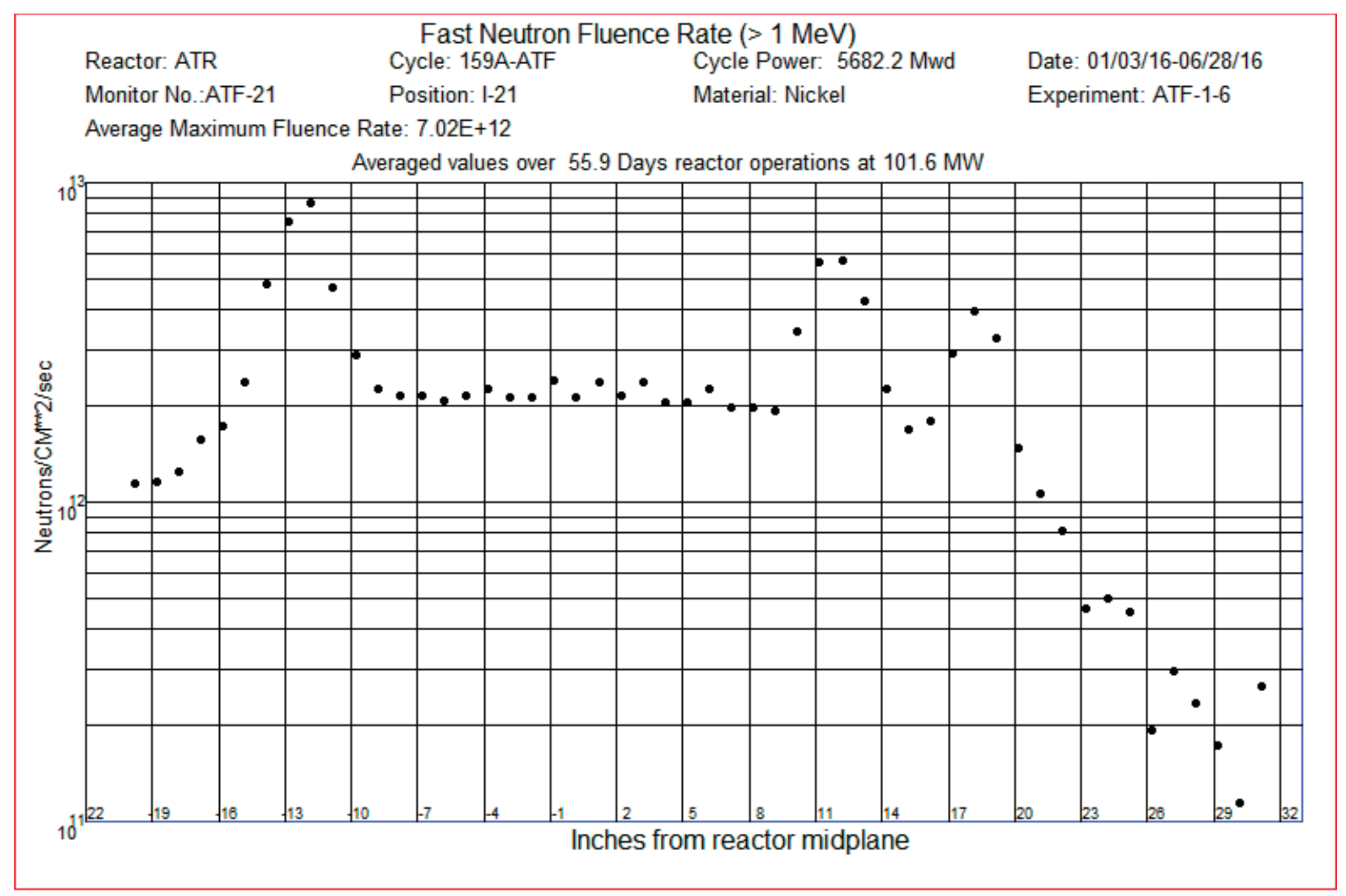




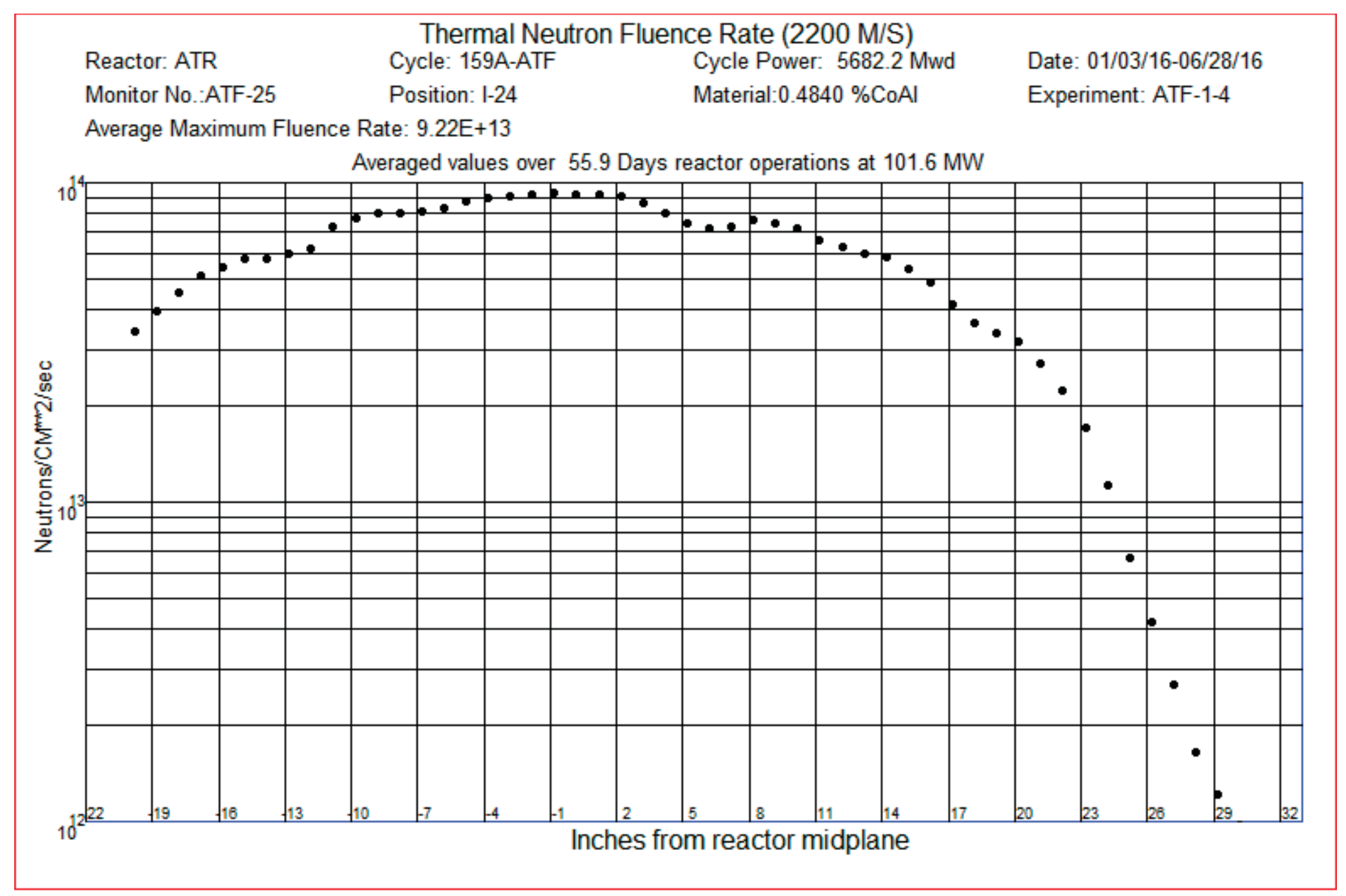




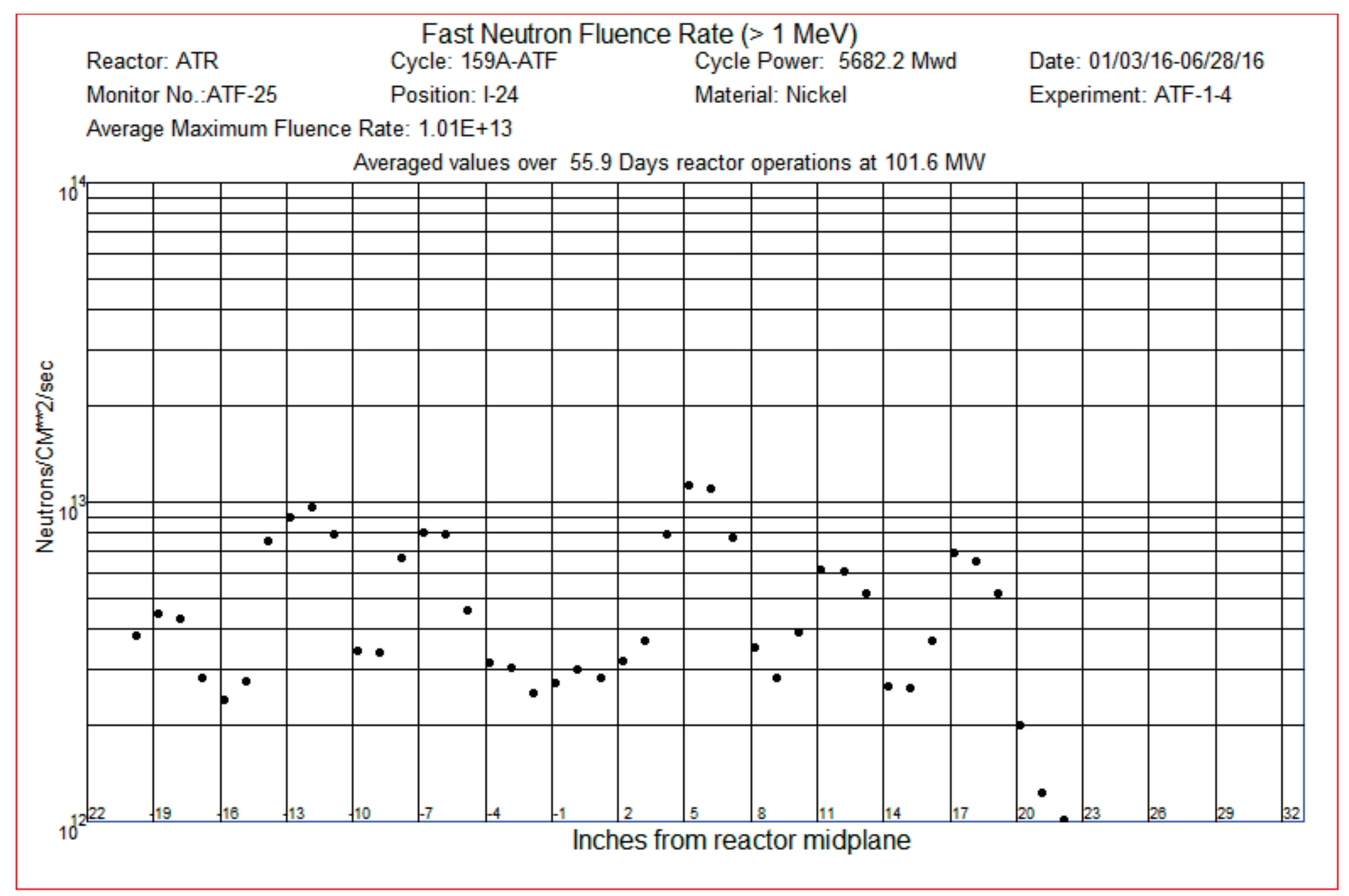




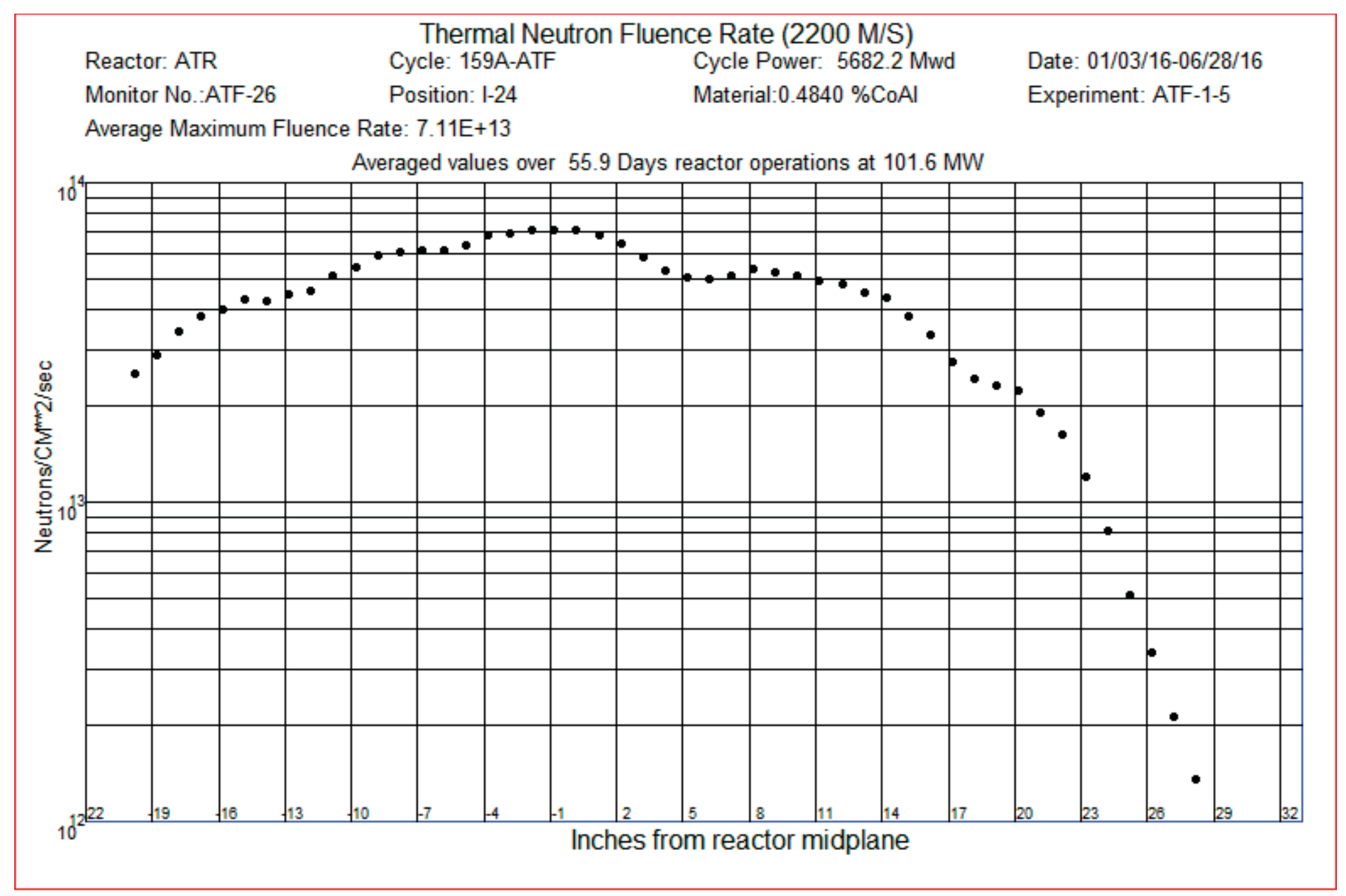




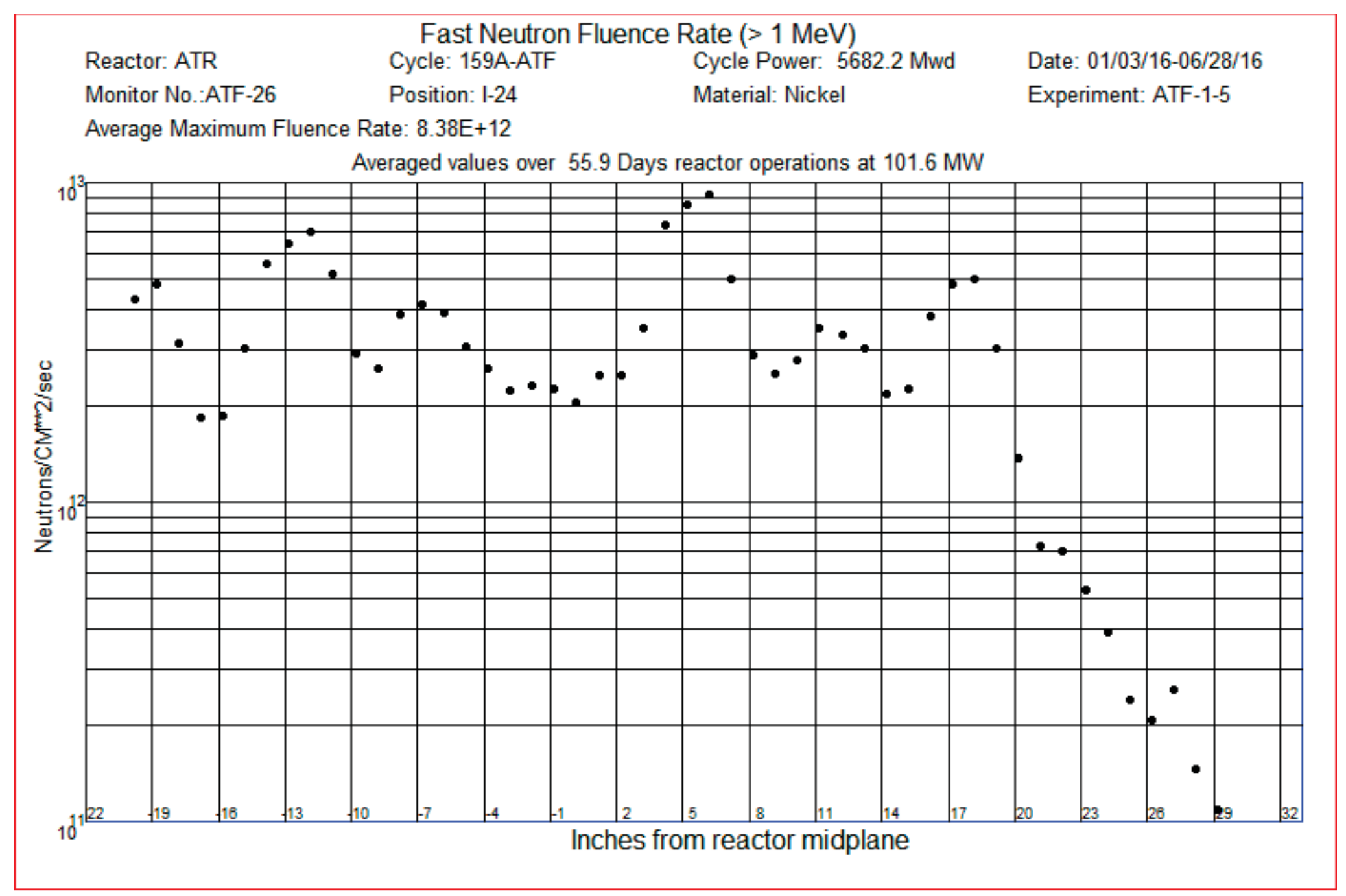




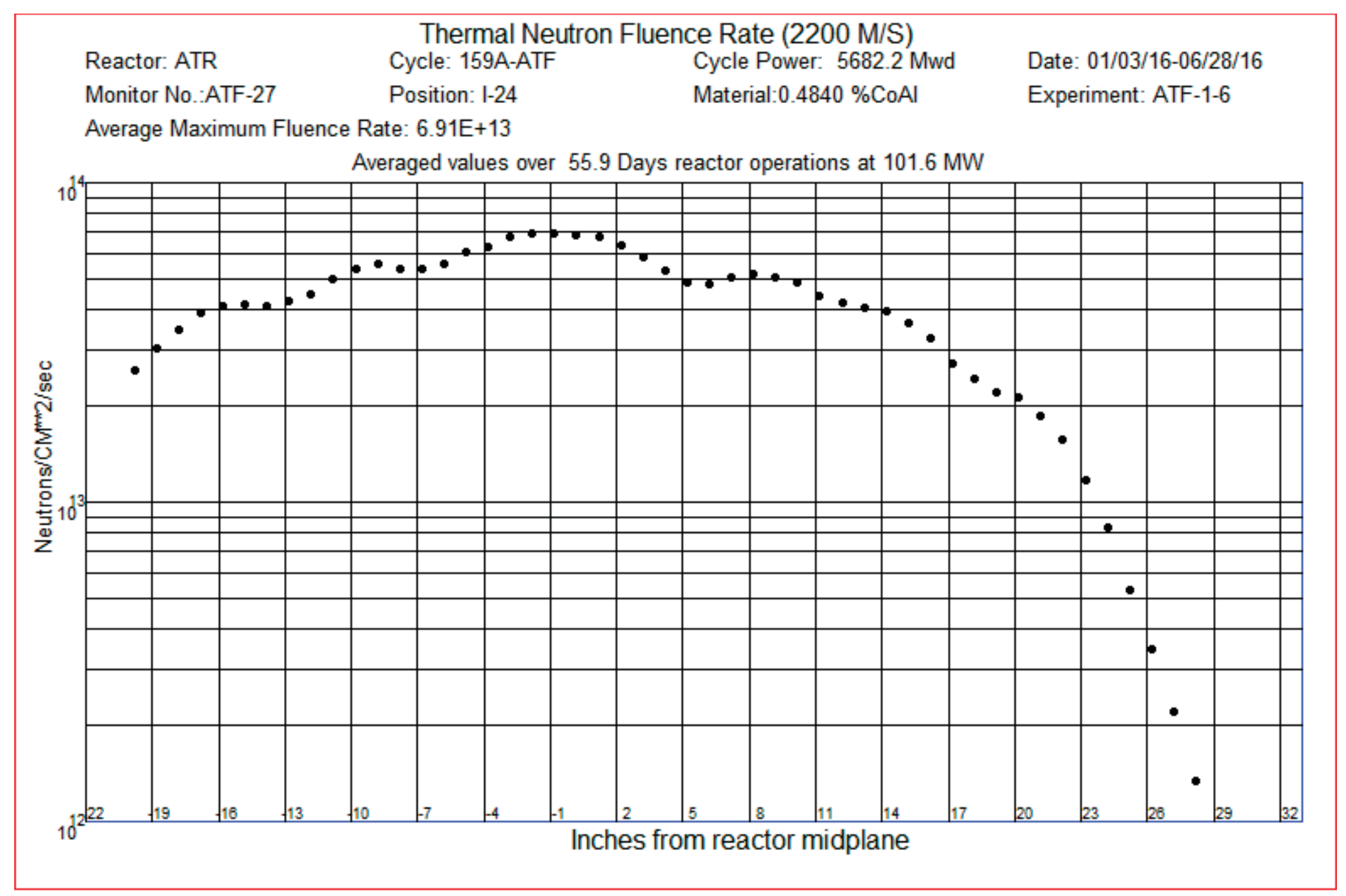




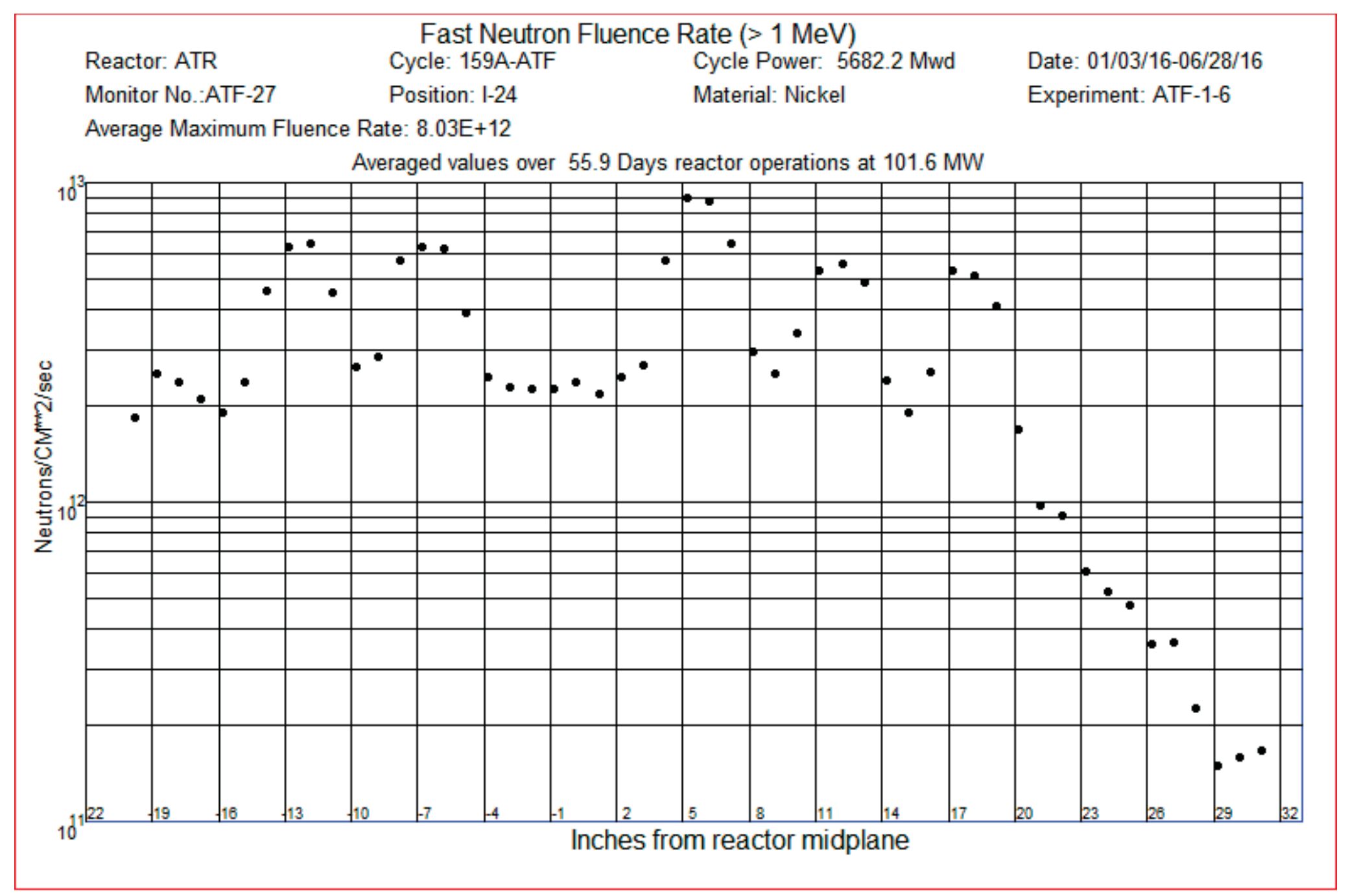

